\title{
A TEORIA DOS PROSPECTOS E O EFEITO FRAMING, E A SUA APLCAÇÃO NO PROCESSO DECISÓRIO, O CASO DA COMUNIDADE QUILOMBOLA RAMAL DO CASTELO.
}

\author{
Nome Josué de Lima Carvalho \\ URL \\ http://lattes.cnpq.br/8214132585708396 \\ Instituição/Afiliação \\ UNISA \\ País \\ Brasil \\ Resumo da \\ Biografia \\ Especialista em Contabilidade, formado pela Ufra Tomé-Açu, membro da \\ comissão de meio ambiente do CRC/PA. Atua como professor/tutor na UNISA \\ polo Tomé-Açu com as disciplinas de Sustentabilidade e Meio Ambiente, \\ Liderança, cultura e poder nas organizações e A Evolução da Contabilidade.
}

Contato principal para correspondência.

$\begin{array}{ll}\text { Nome } & \text { Ticiane Lima dos Santos } \\ \text { URL } & \text { http://lattes.cnpq.br/1579287644263493 } \\ \text { Instituição/Afiliação } & \text { UFRA } \\ \text { País } & \text { Brasil } \\ \text { Resumo da } & \text { Possui DOUTORADO em Administração (UNAMA) MESTRADO INTERNACINAL - } \\ \text { Biografia } & \text { UDE (2008) e MESTRADO EM ADMINISTRAÇÃO pela Universidade Federal do Rio } \\ & \text { Grande do Norte- UFRN (2010). graduação em CIÊNCIAS CONTÁBEIS pela UFPA } \\ & \text { (2003), graduação em PEDAGOGIA pela UEPA (2002), ESPECIALIZAÇÃO } \\ & \text { Metodologia do Ensino superior (UEPA), Eco Auditoria (UFPA)). }\end{array}$

Nome

Ynis Cristine de Santana Martins Lino Ferreira

URL

http://lattes.cnpq.br/3907525185920141

Instituição/Afiliação

UFRA

País

Brasil

Resumo da

Biografia

Graduada em Ciências Contábeis pelo Instituto de Estudos Superiores da Amazônia-IESAM (2007). Especialista em Informação Ambiental pelo Núcleo de Meio Ambiente- NUMA/UFPA (2010). Mestre em Gestão dos Recursos Naturais e Desenvolvimento Local na Amazônia pelo NUMA/UFPA (2011). Doutora em Administração (PPAD) na Universidade da Amazônia-UNAMA (2018).

Nome
Instituição/Afiliação
País
Resumo da
Biografia
Nome
URL
Instituição/Afiliação
País
Resumo da
Biografia

Giselle Midory Farias Sato

UFRA

Brasil

Contadora formada pela Ufra Tomé-Açu, profissional especializada em contabiidade aplicada ao terceiro setor, especificamente em associações de agricultores rurais

Mario Vasconcellos Sobrinho

http://lattes.cnpq.br/7843288526039148

UFPA/UNAMA

Brasil

Economista (1987), Mestre em Planejamento do Desenvolvimento pelo Núcleo de Altos Estudos Amazônicos (NAEA) da Universidade Federal do Pará (2000). PhD em Estudos do Desenvolvimento (2007) pelo Centre for Development Studies 
(CDS), University of Wales Swansea (Reino Unido). Pós-doutor em Gestão

Pública e Governo (2015) pela EAESP da Fundação Getúlio Vargas (FGV).

\section{RESUMO}

O estudo tem como objetivo analisar a influência da teoria dos prospectos e o efeito framing decisão risco, na comunidade quilombola do ramal Castelo. Intentou-se demonstrar que o processo decisório na comunidade estudada é fundamentado sobretudo em fatores comportamentais. Em relação aos procedimentos metodológicos utilizados, desempenhou-se a pesquisa descritiva, com análise, observação e registro dos fatos. Foram aplicados questionários de dois tipos (I e II), para verificar os vieses relativos a escolhas, sempre com duas opções que levavam o decisor a arriscar ou não arriscar. Os resultados obtidos nas duas primeiras questões apresentaram o efeito framing, pois nas questões apresentadas como ganhos, os respondentes apresentavam uma aversão ao risco, mas quando os mesmos problemas eram exibidos diante de situação de perda, a maioria assumia riscos para evitar qualquer tipo de perda, na terceira questão os dois questionários apresentaram uma resposta estatisticamente idêntica, nem assumindo o risco e nem deixando de assumir, aceitando um meio termo entre as opções.

Palavra-Chave: Efeito Framing, Comunidade Quilombola, Teoria dos Prospectos.

\section{INTRODUÇÃO}

Toda organização, para crescer e sobreviver no mercado precisa tomar decisões, e estas nem sempre são simples ou obtém sucesso. Uma escolha errada pode comprometer todo o futuro de uma entidade, causando grandes impactos ou até mesmo o fim de sua existência. Kahneman e Tversky apud Pontes et al. (2014) afirmam que um indivíduo possui decisões diversificadas no momento que se depara com diferentes elaborações de um mesmo problema. Os referidos autores desenvolveram a Teoria do Prospecto que objetiva estudar o processo decisório em diferentes situações, assim como aos relacionados com o efeito framing.

Para Mayer e Avila (2003), o efeito framing é a chance de influenciar um indivíduo em sua tomada de decisão, com mudanças em sua formulação, mas perante um mesmo problema. Nesse sentido, a decisão acaba sendo, em parte, monitorada pela forma de como é exposto o problema.

$\mathrm{Na}$ literatura acadêmica diversos autores tratam sobre como o indivíduo e/ou grupo se relacionam com a agricultura e a exploração de recursos naturais, sendo que através de uma breve definição pode se considerar essa relação como a artificialização pelo homem do meio natural, representado como todas as atividades de exploração das terras (BARROS, 1975). As práticas agrícolas são comuns a diversos grupos de diversas regiões do Brasil, com o intuito de fortalecer essas práticas a tomada de decisão se demonstra como uma ferramenta essencial de controle e gerenciamento, independentemente do tipo de produção ou das características de quem a pratica.

Entre os muitos praticantes de atividades rurais, as comunidades e povos tradicionais também se utilizam desse meio para a sua subsistência. Podem ser definidos de acordo com Decreto $n^{\circ}$ 6.040/2007 como grupos que são diferenciados culturalmente, e se reconhecem como tais. Esses grupos possuem suas próprias formas de organização social, ocupando e usufruindo de territórios que são condicionados para a sua reprodução cultural, social, religiosa, ancestral e econômica, utilizando os seus conhecimentos, inovações e práticas gerados para a transmissão pela tradição (BRASIL, 2007). Conforme estudo feito por (SILVA E SOUZA, 2009) se estimam no Brasil que atualmente 4,5 milhões de pessoas pertencem a comunidades tradicionais, e ocupam cerca de $25 \%$ do território nacional. 
Dentre as diversidades de povos tradicionais, este trabalho tem por objeto de estudo investigar a importância da figura dos povos quilombolas e as suas relações com o processo de tomada de decisão diante de problemas propostos. Esses grupos étnicos também são conhecidos como "Comunidades Remanescentes Quilombolas" são constituídas pelos descendentes dos escravos negros que, no processo de resistência à escravidão, originaram grupos sociais que ocupam um território comum e compartilham características culturais, sociais e econômicas até os dias de hoje. (FUNDAÇÃO PALMARES, 2007)

A tomada de decisão como já exposto, possibilita ao gestor opções de melhor gerenciamento em decisões cujo teor é a aplicação e o retorno dos recursos, sejam eles financeiros, matéria prima, entre outros. Com base nesse pressuposto, é possível ressaltar a importância que a tomada de decisão gera a qualquer empreendimento, mesmo que seja de pequeno porte. Eis estão a oportunidade de gestores rurais em utilizar essa ferramenta no seu dia a dia, para alavancar financeiramente seus resultados, promovendo também um controle efetivo de matéria prima, recursos naturais, e gastos relacionados às atividades agrícolas.

Sendo assim, a pesquisa objetiva analisar a influência da Teoria dos prospectos e o efeito framing, na perspectiva de ganhos e perdas, no processo de tomada de decisão na comunidade quilombola ramal do Castelo na região do Marupaúba, localizada no município de ToméAçu/PA.

\section{FUNDAMENTAÇÃO TEÓRICA}

\subsection{Comunidades Tradicionais}

O processo de colonização portuguesa a partir do século XVI plasmou características marcantes na população rural, criando um modelo de adaptação ao meio, apesar das diferenças regionais, percebe-se de acordo com (ARRUDA, 1999) que essas comunidades tradicionais possuem características em comum que ainda hoje marcam esses grupos isolados em distintas regiões do Brasil. O autor ressalta ainda que esse fato se deve a grande influência de populações indígenas e ao caráter cíclico e irregular do avanço da sociedade nacional sobre o interior do país.

Através do decreto 6.040/2007 se aferiu definições relevantes as comunidades tradicionais e como se dá o seu relacionamento com o ambiente ao redor delas. No Art. $3^{\circ}$, inciso II, se define os territórios tradicionais como sendo os espaços necessários para que os grupos se reproduzam culturalmente, socialmente e economicamente, seja de forma temporária ou permanente. Ainda no Art. $3^{\circ}$, no inciso III, o decreto explica a relação dos grupos tradicionais com o desenvolvimento sustentável com intuito de garantir a melhoria da qualidade de vida da geração, progredindo até as futuras gerações.

Em anexo ao decreto se encontra a Política Nacional de Desenvolvimento de Povos e Culturas Tradicionais que tem grande importância na garantia de direitos sociais desses povos, o que bem se pode identificar junto ao seu objetivo:

A PNPCT tem como principal objetivo promover o desenvolvimento sustentável dos Povos e Comunidades Tradicionais, com ênfase no reconhecimento, fortalecimento e garantia dos seus direitos territoriais, sociais, ambientais, econômicos e culturais, com respeito e valorização à sua identidade, suas formas de organização e suas Instituições. (DECRETO Nº.040, 2007)

As técnicas de plantio desenvolvidas por esses grupos também sofrem fortes influências da população indígena (roça consorciada, itinerante, com base na queimada, tipo slash-andburn) e de artefatos como as peneiras, os pilões, o ralo, o tipiti e outros implementos que fazem parte da cultura rústica brasileira. (ARRUDA, 1999) 


\title{
2.1.1. Comunidades Quilombolas
}

O termo quilombo possivelmente se refere a um conceito próprio dos africanos bantos que vem sendo modificado através dos séculos, o significado está relacionado a acampamentos de guerreiros nas florestas.

\begin{abstract}
Na tradição popular no Brasil há muitas variações no significado da palavra quilombo, ora associado a um lugar ("quilombo era um estabelecimento singular"), ora a um povo que vive neste lugar ("as várias etnias que o compõem"), ou a manifestações populares, ("festas de rua"), ou ao local de uma prática condenada pela sociedade ("lugar público onde se instala uma casa de prostitutas"), ou a um conflito (uma "grande confusão"), ou a uma relação social ("uma união"), ou ainda a um sistema econômico ("localização fronteiriça, com relevo e condições climáticas comuns na maioria dos casos") (Lopes, Siqueira e Nascimento 1987: 15). A vastidão de significados, 12 como concluem vários estudiosos da questão,13 favorece o seu uso para expressar uma grande quantidade de experiências, um verdadeiro aparato simbólico a representar tudo o que diz respeito à história das américas. A conquista da América não produziu uma única história; produziu, sim, "árvores de histórias". Os negros estavam inseridos no movimento colonial de "descobrir, resgatar, povoar e governar - só que como povos dominados" (GIUCCI, 1992)
\end{abstract}

O quilombo no Brasil teve a sua origem na época colonial como representação a resistência dos africanos ao escravismo praticado no período. E retorna à cena política no final dos anos 70, durante a redemocratização do país. Trata-se, portanto, de uma questão persistente, tendo na atualidade importante dimensão na luta dos afrodescendentes. (LEITE, 2000)

Como já foi supracitada, a divisão territorial é uma característica marcante principalmente na zona rural nacional, contudo os povos de descendência africana não foram contemplados na primeira lei das terras em 1850. Somente a partir da Constituição Federal 1988, foram promulgadas as Disposições Transitórias que preveem o reconhecimento da propriedade das terras dos "remanescentes das comunidades dos quilombos"

\subsection{Teoria dos Prospectos}

Os indivíduos possuem decisões diversificadas a cada nova situação, e podem mudar de acordo com a apresentação do problema (LIMA, 2003). Dessa forma, várias são as teorias que nasceram com objetivo de explicar a influência que existe na forma de demonstrar o problema sobre a tomada de decisão do ser humano.

Nesse segmento, a teoria dos prospectos tem a sua importância no momento em que demonstra os vieses de percepção dos tomadores de decisão a contar de sua familiaridade com contextos problemas e conteúdos relativos a eles.

A teoria dos prospectos forma um apoio teórico essencial, no que diz respeito ao entendimento comportamental dos indivíduos. Macedo e Fontes (2009) entendem que esta teoria é capaz de esclarecer vieses intelectivos no processo decisório, tornando-se assim uma importante base às finanças.

Ainda no entendimento de Macedo e Fontes (2009), a decisão possui papel fundamental em uma organização, seus reflexos podem ser os melhores casos consiga resolver o problema, além de possuir a capacidade de afetar diretamente a vida de muitos indivíduos envolvidos.

A teoria de Kahneman e Tversky (1979) é um exemplo de teorias que objetivam uma melhor compreensão no momento da decisão, em relação ao comportamento do tomador de decisão. De acordo com os psicólogos, o processo decisório em momento de risco é compreendido como uma opção entre prospectos ou empreendimentos de risco. 
Segundo a teoria dos prospectos no que diz respeito à Mineto (2005), o indivíduo possui duas fases de utilização no processo decisório, são elas: a fase de edição dos prospectos de risco e a fase de avaliação dos mesmos. A primeira fase equivale a um primeiro exame das possibilidades que são oferecidas no momento da exposição das possibilidades. A segunda fase acontece a avaliação dos prospectos editados, sendo escolhido o de maior valor.

Os psicólogos Kahneman e Tversky (1979) desejavam entender como as pessoas realizam escolhas de risco, desde as opções intuitivas sem considerar nada em relação à racionalidade delas. A teoria dos prospectos surgiu como uma opção à teoria da utilidade esperada, sendo a certeza do que claramente as pessoas dão importância, sendo capaz de influenciar em suas decisões, não é a consequência esperada de sua escolha, mas sim as suas diferentes atitudes perante ganhos e perdas.

Conforme Lima (2003), a teoria dos prospectos, em sua essência, relata distintos estados mentais que são capazes de influenciar no processo decisório. Nesse sentido, a repugnância ao risco acontece somente quando se trata de ganhos, mas a partir do momento em que se fala em probabilidade de perda, há uma tendência em que a pessoa se arrisque.

Kahneman e Tversky (1979) afirmam que as pessoas possuem duas fases diferentes para decidir algo. A primeira fase é a edição do problema conforme as regras que servem para facilitar o processo decisório, e a segunda fase o tomador de decisão distribui padrões e princípios e opta pelo prospecto de maior valor.

A teoria dos prospectos surgiu como uma crítica aos modelos de processo decisório e está fundamentada pela razão de que para o igual valor de ganhos e perdas, o entendimento de valor em condições de perdas é claramente maior do que em condições de ganhos associados. (SANTOS; BOTELHO, 2011)

\subsection{Efeito Framing.}

Decisões em todo momento são tomadas, e estas nem sempre acarretam em um resultado esperado. O modo como é tratado o processo decisório pelo ser humano é fator influenciador no resultado final. Tais decisões podem sofrer influências de acordo como o problema é exposto ao decisor.

$\mathrm{O}$ efeito de enquadramento, ou efeito framing, se refere ao fato de que o processo decisório pode ser influenciado pelo modo como o problema é retratado e como as opções são expressas. De acordo com Mayer e Avila (2010), o efeito framing é a chance de influenciar a decisão de uma pessoa, apresentando as informações de modo verdadeiro, sem alterações, mas com mudanças sutis em sua forma, em um mesmo problema.

Kahneman e Tversky (1979) desenvolveram a Teoria do Prospecto (ou teoria da perspectiva), como forma de resposta aos modelos normativos do processo de tomada de decisão. O efeito framing foi formulado nesta teoria de Kahneman e Tversky (1979) e interpreta a presença de diferentes respostas das pessoas perante um mesmo problema decisório devido às mudanças no método de expor o problema. De acordo com os autores, o indivíduo muda de postura pela forma de como é apresentado o problema.

De acordo com Carvalho Junior, Rocha e Bruni (2010), o efeito framing determina a noção de que o indivíduo possui diferentes respostas a um mesmo problema desde que haja alterações em sua exposição. Já para Ferreira Jr (2012), o jeito como a pessoa compreende o problema está relacionado com diferentes variáveis ambientais, são elas os hábitos da pessoa ou sociedade em geral, o código de ética acordado, as normas e leis, entre outros. 
No entendimento de Daft apud Longaray e Beuren (1999), são várias as situações que influenciam no processo decisório, logo as pessoas precisam estudar melhor as probabilidades de errar, levando em consideração diferentes variáveis como: certeza, incerteza, risco e imprecisão.

Kahneman e Tversky (1979) desenvolveram um exemplo sobre o modo de anunciar um problema. Trata-se de como comunicar o impacto de uma epidemia na cidade.

Acham-se dois planos para conter certa enfermidade que foi responsável pela infecção de seiscentas pessoas e é necessário que você opte por um desses planos. Se optar pelo primeiro plano, é provável que duzentas pessoas sejam salvas, entretanto se escolher a segunda opção há uma possibilidade que um terço sejam salvos, porém dois terços perdem a vida. Qual sua decisão quantos as duas opções?

Verificou-se que a maior parcela de indivíduos preferiu o primeiro plano. Porém, e a situação fosse apresentada como a opção entre um terceiro plano, no qual quatrocentas pessoas perderiam a vida, e um quarto plano que seiscentas pessoas morreriam, tendo dois terços de chance, e livra todas as seiscentas com apenas um terço de chance, a maioria dos indivíduos preferem o quarto plano.

Nota-se que estamos falando de um mesmo problema, no entanto, estruturado de um jeito diferenciado, o que afetou na tomada de decisão de muitas pessoas.

\subsubsection{Risco e retorno}

Conforme definição de Levin, Gaeth e Schreiber apud Martins et al. (2013) "Há três tipos de efeito framing: o de atributo que se refere ao sucesso e ao insucesso; o de Objetivo que se refere a à mensagem persuasiva e o efeito framing de escolha sob o risco. A relação de risco e retorno está intimamente ligada a diversas organizações, principalmente aquelas ligadas a finanças, diariamente grandes e pequenos investidores trabalham seu capital com o intuito de receber ganhos e evitar perdas.

Ao se analisar estudos anteriores com essa temática, percebe-se que de um modo geral se chegou a um denominador comum no sentido que os investidores/tomadores de decisão "são afetos ao retorno, mas não aos riscos, o que leva a conclusão que somente investem em ativos mais arriscados, se esperarem obterem maior retorno nesse investimento. " (MARTINS et al., 2012)

Segundo Markowitz apud Macedo Jr (2003) risco define-se como uma variável eventual e se refere ao modo como risco e retorno reagem no momento em que ativos suplementares são incluídos a uma carteira.

Em todo momento decisões são tomadas sem muitos obstáculos, e estas geralmente têm seus resultados simples de calcular. Todavia nem todo processo decisório obtém sucesso, isso quando decisões são tomadas erroneamente, causando severas consequências.

O indivíduo, quando deparado com uma situação de risco, ou possui seu retorno incerto, não ordena suas escolhas de um modo que caracterize seus problemas. Pompian (2006) diz que as pessoas preferem métodos menos racionais, em um experimento de estabelecer o sentido da ação, conforme suas necessidades básicas. 
Kahneman e Tversky (1979) entendem que a aversão à perda tem como base a apuração de que o indivíduo sofre mais com uma perda do que a satisfação de obter um ganho. Nesse sentido, observa-se que o ser humano não teme tanto ao risco, mas à perda.

Ainda no entendimento de Kahneman, a aversão à perda é concedida ao fato de que há uma maior atenção para os prejuízos do que para os ganhos, logo, esse comportamento tende a influenciar no processo decisório de várias maneiras.

As pessoas tendem a assumir riscos no interesse de não perder, isto é, tratando-se de vantagens o indivíduo tem aversão ao risco, porém perante uma probabilidade de perda, há uma aversão à perda (DAFT, 1999) apud Longaray e Beuren (1999).

É comum observar que um grande número de indivíduos não tem interesse em arriscarse objetivando um ganho, principalmente quando este ganho implique em possibilidade de perdas. As pessoas preferem perspectivas confiáveis, certas.

Nesse segmento surge um efeito denominado certeza. As pessoas possuem diferentes comportamentos perante o processo de tomada de decisão, quando é incluída a certeza na formulação do problema. Neste efeito, quando há certeza em relação a ganhar ou perder, o comportamento das pessoas é totalmente diferente em ambas as situações

\subsection{Tomada de Decisão}

O processo decisório é um processo intelectivo resultante da escolha de uma alternativa em meio a várias outras. Para Mintzberg et al apud Façanha (2007, p. 32) "o processo de tomada de decisão é um conjunto de ações e elementos dinâmicos que começa com o reconhecimento de um estímulo que exige ação e finaliza com uma decisão."

Desse modo, tomar decisão está intimamente interligado com escolhas, para que essas escolhas possam ser satisfatórias, se faz necessárias informações tempestivas e confiáveis. O processo de escolha muitas vezes é dificultado pela escassez de informação que o sustente (PONTES et al, 2013), quanto mais escassas essas informações, mais difícil é para tomar uma decisão. Surge então a oportunidade da utilização das ferramentas gerenciais, que possibilitam ao tomador uma oportunidade de encontrar uma base para a sua decisão.

Segundo Pereira e Fonseca (1997), a decisão é um procedimento sistêmico, contraditório e contextual, impossibilitada de ter sua análise isolada das circunstâncias que a contornam. O que significa que a tomada de decisão não é um processo que se trabalha de maneira isolada, antes para que se possa tomar uma decisão, se faz necessário analisar cada ponto relevante se utilizando do método de visão holística, a fim de definir qual seria a escolha mais "satisfatória"

A forma como a decisão é estruturada representa a percepção do tomador de decisão sobre o elemento essencial que compõem a mesma, para se definir essa percepção se faz necessário entender fatores que influenciam o indivíduo, sejam eles: culturais, pessoais e/ou psicológicos. (SERPA E AVILA, 2014)

Conforme as informações supracitadas, a tomada de decisão é um processo que se comporta de maneira diferenciada, a depender do indivíduo e como o mesmo se relaciona com o ambiente e as situações ao seu redor.

Koontz e O'Donnell (1972) reconhecem a tomada de decisão como sendo o planejamento administrativo, diferente de Simon (1970) que compreende como sendo um processo administrativo. De acordo com Lucena et al. (2011), as probabilidades envolvendo 
um processo de decisão podem ter vários focos, ainda que os resultados apresentados sejam parecidos.

Existem duas teorias principais de tomada de decisão, são elas as teorias racionais e as teorias não racionais. As teorias racionais são de primazia normativa, enxerga o tomador de decisão como uma pessoa de firmeza, já as teorias não racionais são de primazia descritiva, com heurísticas como processo intelectivo, apresentando um formato mais concreto dos processos de tomada de decisão.

Kahneman e Tversky (1979) criticaram a teoria da racionalidade ilimitada do indivíduo. Para eles, a pessoa usa de unidades de natureza humana quando encontram incertezas e situações arriscadas. Alegam ainda que há uma disposição de que os indivíduos apresentam mais repugnância ao risco do que ao ganho, ou seja, não arriscam trocar o certo pelo duvidoso, optando por um ganho pequeno, porém certo, do que um ganho superior, mas com possibilidade de não o alcançar.

\section{PROCEDIMENTOS METODOLÓGICOS}

\subsection{Características Gerais}

Trata-se de uma pesquisa classificada como descritiva com dados analisados de forma quantitativa, pois foram aplicados questionários elaborados com perguntas relacionadas ao processo decisório e o efeito framing na comunidade quilombola estudada.

O objetivo da pesquisa descritiva é a análise, observação e registro dos fatos, sem que haja a intervenção dos pesquisadores. Perovano (2014) diz que a pesquisa descritiva pode ser compreendida como um estudo de caso em que, após colher os dados, realiza-se um estudo do elo entre as variáveis para mais tarde acontecer a definição dos impactos consequentes em uma organização.

\subsection{Lócus}

O estudo foi realizado em uma comunidade quilombola situada no município de ToméAçu/PA, na rodovia PA 140, comunidade Castelo. A comunidade se localiza na região do Marupaúba a aproximadamente $38 \mathrm{~km}$ da sede do município de Tomé-Açu. Foram aplicados questionários a 40 famílias da região, sendo esse o universo total da população, com $100 \%$ de respostas.

Figura 01 Mapa da Comunidade Ramal do Castelo.

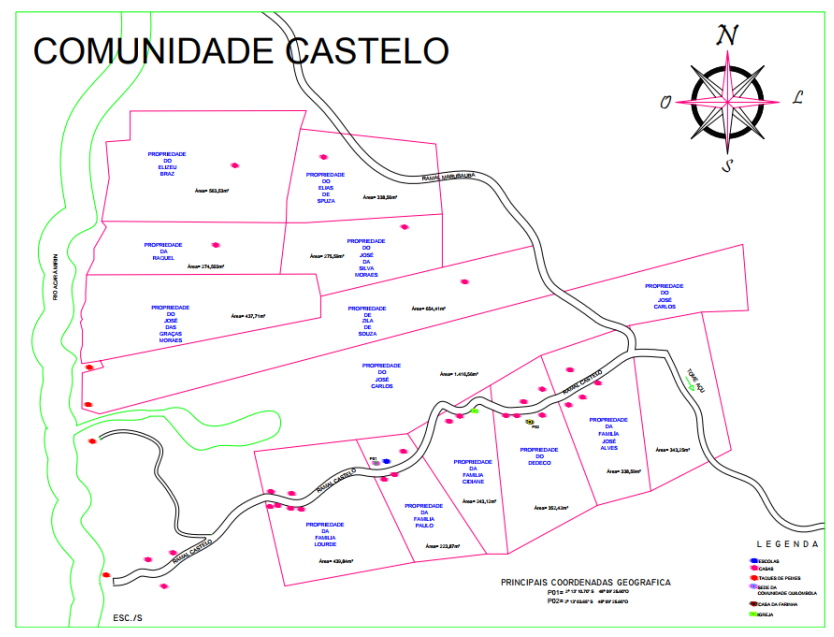




\section{Fonte: Salene Cordeiro}

\subsection{Coleta de Dados}

A coleta de dados foi realizada através de dados tabulados de dois questionários distribuídos no local, estes baseados em Barreto et al. (2013). Para se chegar ao objetivo dessa pesquisa foram elaboradas diversas perguntas, e entre elas métodos de organização e controle para o exercício da atividade agrícola.

Os questionários foram elaborados com perguntas que mostram como as pessoas reagem ao efeito de enquadramento, com os mesmos problemas, entretanto apresentados de forma diferente, em situação de perdas e prejuízos e ganhos e vantagens, com objetivo de entender se o comportamento das famílias quilombolas estudados é influenciado perante as diferentes formas de expor o mesmo problema.

Em ambos os questionários (Tipo I e Tipo II), se intentou verificar os vieses relativos as escolhas, sendo que os mesmos possuem as mesmas perguntas, diferenciando na forma de apresentação das alternativas, uma em forma de ganho e outra em forma de perda. (Quadro 01).

Levando se em consideração que os questionários de Barreto et al. (2013) foi direcionado para um público de graduação e pós-graduação, se fez necessário adaptar o questionário a realidade da comunidade Quilombola, trazendo as alternativas no contexto social do entrevistado, proporcionando entendimento situacional ao entrevistado. 
Quadro 01: Questionários da pesquisa, baseados em Barreto et al. (2013).

1-Você investiu \$ 300,00 (mão de obra) na sua produção de farinha de mandioca. Devido a uma enchente você deverá arcar com alguns custos. Algumas medidas deverão ser tomadas a fim de minimizar as perdas causadas pela "catástrofe". Escolha a alternativa (A ou B) que achar mais conveniente.

Tipo I

( ) Alternativa A: $40 \%$ de chances de recuperar $\$ 100,00$ e $60 \%$ de chances de recuperar $\$ 0$

() Alternativa B: $42 \%$ de chances de recuperar $\$ 100,00$ e $58 \%$ de chances de recuperar $\$ 0$

Tipo II

( ) Alternativa A: $40 \%$ de chances de não recuperar $\mathrm{R} \$ 200,00$ e $60 \%$ de chances de não recuperar $\mathrm{R} \$$ 300,00

() Alternativa B: $42 \%$ de chances de não recuperar $\mathrm{R} \$ 200,00$ e $58 \%$ de chances de não recuperar $\mathrm{R} \$$ 300,00

2-Você produziu uma quantidade de farinha de mandioca que pode lhe render $\mathrm{R} \$ 3.000,00 \mathrm{em}$ condições normais de mercado, porém a produção está em alta e o preço que o atravessador paga está bem abaixo do normal praticado. Diante disso Ihe surgem duas opções:

Tipo I

( ) Plano A: Se essa opção for adotada, consegues receber $\mathrm{R} \$ 1.000,00$ nessa venda

( ) Plano B: Se essa opção for adotada, há 1/3 de probabilidade de que consiga receber os $\mathrm{R} \$ 3.000,00 \mathrm{e}$ $2 / 3$ de probabilidade de perder toda a produção.

Tipo II

( ) Plano A: Se essa opção for adotada, R\$ 2000 mil serão perdidos.

( ) Plano B: Se essa opção for adotada, há $1 / 3$ de probabilidade de que nada seja perdido e $2 / 3$ de probabilidade de que tudo seja perdido.

3. Através de um esforço coletivo em prol da construção de uma sede para a associação a comunidade conseguiu produzir o suficiente pra render um montante de $\mathrm{R} \$ 5.000,00$, porém como a produção foi muito acima do que a demanda pode absorver, surgem 3 opções que podem ajudar a recuperar parte desse esforço envolvido

Tipo I

() Alternativa A: $10 \%$ de chances de recuperar $\mathrm{R} \$ 4.500,00$ e $90 \%$ de chances de poupar $\mathrm{R} \$ 0$

() Alternativa B: $45 \%$ de chances de recuperar $\mathrm{R} \$ 1.500,00$ e $55 \%$ de chances de poupar $\mathrm{R} \$ 0$

( ) Alternativa C: $90 \%$ de chances de recuperar $\mathrm{R} \$ 500,00$ e $10 \%$ de chances de poupar $\mathrm{R} \$ 0$

Fonte: Própria adaptado de bareto et. Al. (2013)

Na tabulação dos dados do questionário foi utilizado o software da IBM SPSS 20, em conjunto com o Software Action Stat integrado ao Microsoft Excel 2016. 


\subsection{Análise e Interpretação}

Conforme expresso nessa metodologia, a análise dos dados foi baseada no estudo de Barreto et al. (2013), sendo que o instrumento de análise se baseou a partir de uma contagem de frequências para cada alternativa das perguntas. Para se testar as hipóteses, se fez necessário utilizar como base o teste de diferenças de proporções apresentado por Stevenson (1981), utilizando como níveis de significância de $5 \%$ a $10 \%$, devendo respeitar o valor de $\mathrm{Z}$ em um teste unicaudal, utilizando os níveis $-1,64 \mathrm{ou}+1,64$ a $5 \%$ de significância e -1.28 ou +1,28 a $10 \%$ de significância.

Na formulação das nossas hipóteses, utilizando como base Barreto et al. (2013), se estabeleceu duas hipóteses bases, sendo elas:

H0: A proporção da escolha de A ou B no questionário Tipo I é igual a proporção no questionário II;

H1: A proporção da escolha da opção de maior certeza no questionário descrito no campo de ganhos é maior que a mesma opção no questionário tipo II, no campo de perdas.

\section{RESULTADOS}

\subsection{Características da Amostra}

Através da análise do universo dessa pesquisa, constatou-se conforme a (Tabela 01) que dentre os respondentes do questionário $100 \%$ cem por cento pertence a Comunidade Castelo, sendo $55 \%$ da amostra do sexo feminino e $45 \%$ do sexo masculino.

Tabela 01: Distribuição de gênero dos entrevistados

\begin{tabular}{|l|l|l|}
\hline Feminino & 22 & $55 \%$ \\
\hline Masculino & 18 & $45 \%$ \\
\hline Total & 40 & $100 \%$ \\
\hline
\end{tabular}

Fonte: Própria.

Dentre a frequência da idade apresentada aos respondentes, constatou-se que: $22,5 \%$ (4 entrevistados) da amostra se encontra na faixa de 23 a 27 anos, $5 \% 2$ entrevistados) de 28 a 32 anos, $10 \%$ (4 entrevistados) de 33 a 37 anos, 15\% (6 entrevistados) de 38 a 42 anos e 47, 5\% (19 entrevistados) na faixa acima de 42 anos. Abaixo a tabela 02, sintetizada da relação entre os questionários respondidos e a forma de distribuição. 
Gráfico 01: Distribuição de Faixa Etária dos Entrevistados

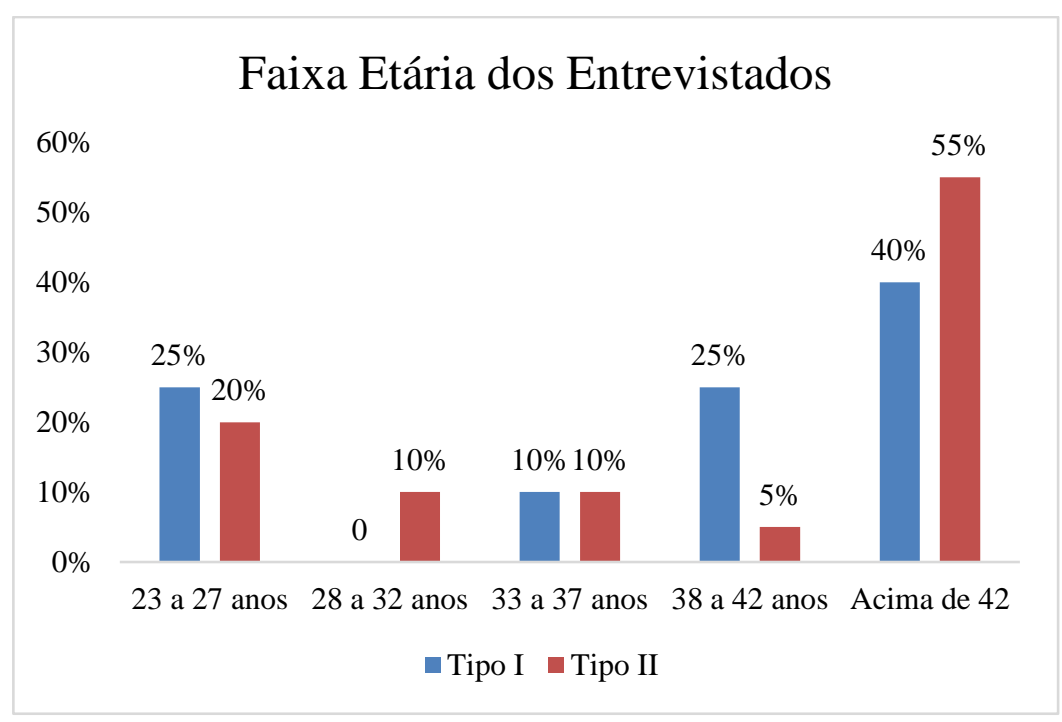

Fonte: Própria

\subsection{Análise Dos Resultados Framing}

Para se realizar a análise do ponto de vista do efeito framing inicialmente se analisou as questões isoladas, comparando as com o estudo de Barreto et al. (2013), como já supracitado na metodologia desse trabalho o questionário utilizado para essa pesquisa, foi baseado no estudo de Barreto et al. (2013), sendo o mesmo adaptado ao público de agricultores do universo dessa pesquisa. Após a análise individual, foram realizadas as análises em conjunto, relativa ao viés (Efeito Framing).

A manipulação da questão I se baseia na diferença de probabilidades. Conforme Barreto et al. (2013) expressa, essa questão se mantiverem os índices percentuais em termos médios, com pouca variação entre as alternativas com o objetivo de analisar se o comportamento dos respondentes seria similar ou distinto do trabalho que essa pesquisa se baseia em forma de análise comparativa do percentual respondido.

O questionário do Tipo I (que trabalha a relação de ganhos), na primeira questão (Questão que trata sobre uma produção de farinha de mandioca no valor de $\mathrm{R} \$ 300,00$ que sofreu perdas referente a uma enchente) em sua alternativa " $A$ " propunha que havia $40 \%$ de se recuperar $\mathrm{R} \$ 100,00$ e $60 \%$ de recuperar $\mathrm{R} \$ 0$. Em contraproposta a alternativa B propunha ao decisor $42 \%$ de recuperar $\mathrm{R} \$ 100,00$ e $58 \%$ de recuperar $\mathrm{R} \$ 0$. O questionário II (trabalha a relação de perdas) propunha ao entrevistado na alternativa "A" que havia $40 \%$ de chance de não recuperar $\mathrm{R} \$ 200,00$ e $60 \%$ de chance de não recuperar $\mathrm{R} \$ 300,00$, no mesmo questionário a alternativa "B" concedia a possibilidade de $42 \%$ de não recuperar $\mathrm{R} \$ 200,00$ e $58 \%$ de não recuperar $\mathrm{R} \$ 300,00$.

Conforme o estudo utilizado como base dessa pesquisa de Barreto et al. (2013), é importante ressaltar que em ambos os casos a alternativa " $A$ " possuía o mesmo valor esperado, o que também se reflete na alternativa "B". Ressaltando ainda que em ambos os casos a alternativa "B" gerava o maior valor esperado percentual. Desse modo, nos questionários foi mantido o valor esperado em cada alternativa, configurando as alternativas como iguais, diferindo em pontos de referência distintos, sendo o Tipo I no campo dos ganhos e o Tipo II no campo de perdas. 
Através da análise dessa questão, conforme estudo de Barreto et al. (2013) “Objetivase verificar o comportamento dos respondentes", no que tange a valores médios em observação a Teoria dos Prospectos, se fazendo presente nas alterações do padrão de resposta devido a mudança de cenário se o resultado implica na violação do princípio da utilidade esperada, que afirma que os agentes ponderam as utilidades "a partir das probabilidades de ocorrência de cada um dos resultados possíveis" (BARRETO et al. 2013).

Conforme análise do questionário I, o mesmo trabalha nos termos de recuperação de valor, o que caracteriza o campo dos ganhos, tendo a maioria dos respondentes optado pela escolha mais "certa" (alternativa B), tal fato ao se comparar com estudo base de Barreto et al. (2013) se demonstrou parecido, pois no estudo base a maioria dos respondentes optou pela escolha mais certa (Alternativa B), no entanto difere na frequência de escolhas, pois nesse estudo a questão I obteve $65 \%$ de frequência na alternativa B, e no estudo de Barreto et al. (2013) a frequência de escolha foi $81,94 \%$. No questionário Tipo II que dala sobre perdas, ao falar em valores não recuperáveis, os respondentes em sua maioria se posicionaram de modo diferente, estabelecendo uma relação na maioria de enfretamento ao risco, o que também se assemelha ao estudo base em uma análise comparativa, pois conforme análise de Barreto et al. (2013) os respondentes daquela pesquisa se posicionaram em sua maioria estabelecendo uma posição agressiva diante das perdas.

De posse dessas informações, pode-se concluir que no questionário Tipo I a maioria da amostra dessa pesquisa se comportou optando pelo maior (42\% de recuperar) valor esperado (65,0\% Alternativa B), o que se assemelha a pesquisa base desse estudo, onde a maioria (81,94\% Alternativa B) optou pela maior probabilidade de recuperar (42\% de recuperar). Conforme analise já realizada, o presente estudo se comportou de maneira assemelhada ao estudo de Barreto et al. (2013), apresentando diferença nas frequências.

Ao se analisar a resposta no questionário Tipo II, a amostra dessa pesquisa se comportou reversa aos que responderam ao Tipo I, havendo preferência pela incidência de menor probabilidade (40\% Alternativa A) e de menor valor esperado, esse fato também contrasta positivamente aos fatos e dados obtidos no questionário Tipo II do estudo de Barreto et al. (2013)

Os dados supracitados, estão expostos nas tabelas a seguir, sendo a Tabela 02 obtida na pesquisa desse estudo, e a tabela 03 obtida no estudo de Barreto et al. (2013).

Tabela 02: Tabela referente a questão 01 - Perder ou não recuperar invest.

\begin{tabular}{|l|l|l|l|l|}
\hline Alternativas & Tipo I & $\%$ & Tipo II & $\%$ \\
\hline A & 7 & 35,0 & 12 & 60,0 \\
\hline B & 13 & 65,0 & 8 & 40,0 \\
\hline Total & 20 & 100,00 & 20 & 100,00 \\
\hline
\end{tabular}

Fonte: Própria. 
Tabela 03: Tabela referente a questão 01 - Perder ou não recuperar invest. Barreto et al. (2013)

\begin{tabular}{|l|l|l|l|l|}
\hline Alternativas & Tipo I & $\%$ & Tipo II & $\%$ \\
\hline A & 13 & 18,06 & 41 & 53,25 \\
\hline B & 59 & 81,94 & 36 & 46,75 \\
\hline Total & 72 & 100,00 & 77 & 100,00 \\
\hline Sem resposta & 5 & & 1 & \\
\hline
\end{tabular}

Fonte: Barreto et. al. (2013)

Através dos fatos acima se é possível concluir que se encontrou um padrão diferente nas respostas para cada tipo de questionário (Tipo I e Tipo II), se levando em consideração que houve mudança significativa entre os resultados dos dois tipos de questionários o que configura a evidente presença do Efeito Framing.

Analisando estatisticamente no teste de diferenças de proporções a questão de número 1, apresenta o valor de Z de -1,583119 o que segundo Stevenson (1981), se encontra dentro dos limites de aceitação 5\%, o que significa que nesse nível a hipótese mais aceita seria a H0 (Não havendo diferença que possa ser considerada significante na diferença proporcional. Contudo por se tratar de uma população pequena, ao se analisar no nível de $10 \%$ o valor de $\mathrm{Z}$ ultrapassa os limites de significância $(-1,28)$, confirmando a Hipótese H1, e consequentemente atestando a ocorrência do Efeito Framing neste caso da questão 01.

A questão dois também baseada no estudo de Barreto et al. (2013) trata sobre uma questão típica da Teoria dos Prospectos, buscando através de seu enunciado analisar a posição do decisor diante do risco, utilizando como referência de manipulação um ponto norteador. Assim como na primeira questão, a questão dois apresenta resultados idênticos nos dois questionários, contudo no primeiro trata as perspectivas de ganho e no segundo de perdas.

Essa questão foi baseada na questão de Barreto et al. (2013), sendo que no estudo base era tratada como: "prejuízos de reclamações trabalhistas", e no presente estudo foi tratada como: "prejuízos com a desvalorização da mercadoria produzida", sendo que os valores do estudo base, foram adaptados à realidade local dos quilombolas deste presente estudo. No questionário do estudo de Barreto et al. (2013) o problema é tratado como uma redução de custos, sendo tratado de forma aparente nesse estudo. No questionário I se é tratado como valor poupado, no questionário II o valor é tratado como um valor perdido.

Como já expresso na metodologia desse trabalho o problema apresentado nos dois questionários é o mesmo, sendo que na primeira alternativa do questionário I (A) apresenta a possibilidade de poupar $\mathrm{R} \$ 1.000,00$ diante dos prejuízos, e na segunda opção (Alternativa B) existe a possibilidade $1 / 3$ de poupar os $\mathrm{R} \$ 3000,00$ e de $2 / 3$ de que nada seja poupado. Ao se analisar a referida situação no campo dos ganhos (Questionário Tipo I) percebe-se que segue as projeções realizadas nos estudos de Kahneman e Tversky (1979) e Barreto et al. (2013), pois no framing relativo a recuperação de custos $80 \%$ da amostra buscou a opção que lhe desse mais segurança, o que contrasta com o Efeito Certeza de forma positiva, optando pela alternativa A que garantia a certeza de $\mathrm{R} \$ 1.000,00$ na operação realizada.

Em análise ao questionário Tipo II cuja framing se relacionava a perda de custos, a amostra dessa pesquisa se comportou em sua maioria $(65,0 \%)$ de forma a arriscar para que 
assim tivesse a chance de ter uma perda menor, optando pela alternativa $\mathrm{B}$, que oferecia a probabilidade de $1 / 3$ de evitar totalmente qualquer perda, no entanto havia a chance de $2 / 3$ de tudo ser perdido. A alternativa garantia que $\mathrm{R} \$ 2.000,00$ seriam perdidos foi escolhida pela menor parcela $(35,0 \%)$ da amostra dessa pesquisa.

Conforme análise da questão proposta, percebe-se a influência do efeito Framing, pois ao se apresentar o mesmo problema de uma forma diferente entre ganhos e perdas, dependendo da maneira que o problema é exposto. Nota-se que como o estudo de Barreto et al (2013) percebe-se que a mudança nos termos, apresentou uma mudança significativa na escolha da alternativa. É importante ressaltar que diferente da questão número 1 , a questão de número 2 não há nenhuma opção de maior valor esperado, sendo que as duas opções oferecem o mesmo valor esperado. Configurando assim, que a decisão foi estipulada por preferência.

Os dados aqui expressos estão confirmados coma tabela abaixo, em comparativo com a tabela da pesquisa de Barreto et al. (2013):

Tabela 04 - Tabela referente a questão 02 - Desvalorização pelo mercado - prejuízos.

\begin{tabular}{|l|l|l|l|l|}
\hline Alternativas & Tipo I & $\%$ & Tipo II & $\%$ \\
\hline A & 16 & 80,0 & 7 & 35,0 \\
\hline B & 4 & 20,0 & 13 & 65,0 \\
\hline Total & 20 & 100,00 & 20 & 100,00 \\
\hline
\end{tabular}

Fonte: Própria

Tabela 05 - Tabela referente a questão 01 - Prejuízos com reclamações trabalhistas Barreto et al. (2013)

\begin{tabular}{|l|l|l|l|l|}
\hline Alternativas & Tipo I & $\%$ & Tipo II & $\%$ \\
\hline A & 53 & 69,74 & 23 & 29,49 \\
\hline B & 26 & 30,26 & 55 & 70,51 \\
\hline Total & 76 & 100,00 & 78 & 100,00 \\
\hline Sem resposta & 0 & & 0 & \\
\hline
\end{tabular}

Fonte: Barreto et al. (2013)

Ao se realizar teste estatístico de diferença de probabilidades nessa questão, a nível de significância de $5 \%$, foi possível confirmar a presença do efeito framing, pois a manipulação do ponto de referência em comparação a forma de apresentação do problema afetou a decisão dos membros da comunidade quilombola apresentando um cálculo de Z 2,878619 o que significa a anulação da Hipótese H0 que infere que as proporções são nulas entre si, o que significa a adoção da Hipótese H1. Confirmando com esse resultado o Principio obtido na Teoria dos prospectos.

Conforme a sequência das duas primeiras questões, a terceira também era a mesma questão nos dois questionários (Tipo I e Tipo II), porém a forma como era apresentada diferia de uma questão para a outra. $\mathrm{O}$ primeiro questionaria contém em suas alternativas o termo poupar, e o segundo questionário contém o termo perder, tal proposta segue os mesmos 
princípios das duas primeiras questões, para justamente analisar a influência da Teoria dos Prospectos na amostra da referida pesquisa.

Para o questionário Tipo I, a alternativa "A" oferecia a oportunidade mínima de $10 \%$ de poupar R \$ 4.500,00 e 90\% de chance de nada ser poupado. A alternativa "B" propunha ao decisor, uma espécie de meio termo entre ganhar e perder, pois propunha $45 \%$ de chance de poupar R \$ 1.500,00 e 55\% de poupar R $\$ 0$. Por fim, a alternativa " $\mathrm{C}$ " oferecia ao quilombola a opção de $90 \%$ de poupar R $\$ 500,00$ e $10 \%$ de poupar R $\$ 0$.

No questionário Tipo II o problema era o mesmo, sendo tratado no campo de perdas. A alternativa "A" apresenta a opção de $10 \%$ de perder R $\$ 500,00$ e de $90 \%$ de perder o montante de R $\$ 5.000,00$, a alternativa "B" assim como no questionário I, apresenta uma opção que pode ser considerada mediana, diante das outras duas, sendo que a mesma apresenta a opção de $45 \%$ de perder $\mathrm{R} \$ 3.500,00$ e $55 \%$ de perder $\mathrm{R} \$ 5.000,00$. Por fim, a alternativa " $\mathrm{C}$ " apresentava as opções dentro do questionário que ofereciam maior propensão ao risco, de modo que a alternativa demonstrava $90 \%$ de chance de perder $\mathrm{R} \$ 4.500,00$ e $10 \%$ de chance de perder apenas $\mathrm{R} \$ 500,00$.

Para que se houvesse a percepção da Teoria dos prospectos nessa alternativa, se faz necessários que os respondentes variassem em suas respostas, conforme a manipulação, sendo necessário que a resposta diante do campo de perdas e ganhos, divergissem, comprovando assim teoria nessa terceira questão. No entanto, os resultados obtidos nessa pesquisa seguem conforme o estudo de Barreto et al. (2013), diferindo de Silva et. al. (2009) que evidenciou a influência do Efeito Framing e da Teoria dos Prospectos, sendo que os resultados aqui obtidos se centralizaram na resposta "B", tanto no questionário I, quanto no II, e a diferença de probabilidades é nula, sendo o valor de $\mathrm{Z} 0$ no teste, o que implica a adoção da Hipótese $\mathrm{H} 0$, que afirma que os respondentes dos dois questionários não diferiram estatisticamente, o que implica dizer que as respostas foram semelhantes, não evidenciando o Efeito Framing na terceira questão.

As tabelas abaixo, demonstram os resultados obtidos nesse estudo em comparativo com o estudo de Barreto et al. (2013).

Tabela 06: Tabela referente a questão 03 - Vendas não absorvidas pelo mercado - Prejuízo

\begin{tabular}{|l|l|l|l|l|}
\hline Alternativas & Tipo I & $\%$ & Tipo II & $\%$ \\
\hline A & 4 & 20,0 & 2 & 10,0 \\
\hline B & 14 & 70,0 & 15 & 75,0 \\
\hline C & 2 & 10,0 & 3 & 15,0 \\
\hline Total & 20 & 100,00 & 20 & 100,00 \\
\hline
\end{tabular}

Fonte: Própria 
Tabela 07: Tabela referente a questão 03 Barreto et al. (2013) - Prejuízo Judicial.

\begin{tabular}{|l|l|l|l|l|}
\hline Alternativas & Tipo I & $\%$ & Tipo II & $\%$ \\
\hline A & 18 & 23,38 & 13 & 16,67 \\
\hline B & 42 & 54,55 & 47 & 60,26 \\
\hline C & 17 & 22,08 & 18 & 23,08 \\
\hline Total & 77 & 100,00 & 78 & 100,00 \\
\hline
\end{tabular}

Fonte: Barreto et al. (2013)

Conforme expresso nos resultados dessa pesquisa, se foi possível notar uma diferença percentual nos resultados da primeira questão, para confirmar a hipótese, foi necessário efetuar um teste de diferença de proporcionalidade, onde a nível de 5\% não se pode constatar diferença relevante estatisticamente, no entanto, como bem expressa Stevenson (1981) como o universo dessa pesquisa é pequeno cabe o teste a nível de $10 \%$, onde se identificou uma diferença proporcional na escolha da alternativa, a depender de como ela era expressa ao decisor (Ganhos ou perdas), evidenciando a presença do efeito framing. Na segunda questão a diferença das proporções a nível de 5\% foi significativa, evidenciando o efeito framing entre os entrevistados. E por fim, na terceira questão a maioria dos entrevistados tanto do questionário I quanto o II, apresentaram uma frequência estatisticamente idêntica, não evidenciando a presença do efeito framing entre os respondentes.

Para o próximo capitulo as nossas considerações finais.

\section{CONSIDERAÇÕES FINAIS}

Em uma visão geral, notou-se que é presumível que haja uma mudança na decisão se ocultada for a possibilidade de perder, isto porque as famílias questionadas podem ser influenciadas pelo efeito certeza e ter a preferência pela alternativa mais provável.

Como podemos verificar nos resultados deste trabalho, há sempre duas opções, e elas levam o tomador de decisão a arriscar ou não arriscar, dependendo do modo como o decisor entende e avalia a situação. De forma geral, a pesquisa atendeu aos seus objetivos, pois conseguiu analisar a influência da teoria dos prospectos e efeito framing na perspectiva de ganhos e perdas no processo decisório da comunidade estudada. Notou-se que há um impacto nas escolhas do decisor a cada situação diversificada, pois essas escolhas podem mudar dependendo de como o problema é apresentado.

Foi identificado que o atual método decisório da comunidade é baseado em fatores comportamentais, com atitudes e comportamentos influenciadores no processo de decisão. Verificou-se que diante das duas primeiras questões do questionário, os quilombolas que compõe a amostra desta pesquisa apresentaram o impacto do efeito framing, pois ao se tratar de ganhos possuíam uma aversão a assumir riscos, e quando os mesmos foram expostos diante de situação de perdas, assumiram em sua maioria o risco no intuito de evitar qualquer perda.

O estudo atendeu também ao problema de pesquisa, ao identificar que a reação dos povos tradicionais quilombolas da região estudada foi diferenciada e influenciada pelo método em que foi apresentado o problema, com decisões diversificadas a cada nova situação, dessa forma possuindo características de influência da teoria dos prospectos e efeito framing.

Este formato de estudo possui grande influência e é indispensável no objetivo da compreensão de fatores relativos a forma de entendimento dos gestores e líderes. À vista disso, almejou-se, com os resultados deste estudo, nortear os líderes quilombolas do ramal Castelo 
para uma maior atenção ao processo decisório, visto que assim os mesmos podem ter as primeiras informações para tomar decisões que os direcionem aos seus objetivos.

Para novas pesquisas, sugere-se um estudo sobre contabilidade comportamental com profissionais da contabilidade que estão iniciando sua vida no mercado de trabalho, visto que a tomada de decisão pode ser considerada como planejamento administrativo, e seus planos e decisões têm o poder de influenciar o alcance de seus objetivos e sucesso profissional.

\begin{abstract}
The study aims to analyze the influence of prospect theory and framing effect on a Quilombola community at Castelo extension. Was attempted demonstrate that the decision-making process on the studied community is based about everything in behavioral factors, thus. In relation to the methodological procedures used, was played the descriptive research, with analysis, observation and records of the facts. Were applied questionnaires of two types (I and II) to verify the bias related to the choices, always with two options that led the decision-maker to risk or not. The results obtained on the two first questions presents the framing effect, because on the presented questions as gain, the respondents presented an aversion to the risk, but when the same problems were exhibited against the situation of loss, most took risks to avoid any kind of loss. On third question, the two questionnaires neither presented an answer statistically identical, not assuming the risk and neither letting to assume, accepting a half term between the options.
\end{abstract}

Keywords: Framing Effect. Quilombola Community. Prospectus Theory.

\title{
REFERÊNCIAS
}

ARRUDA, R. (1999). "Populações Tradicionais" E A Proteção Dos Recursos Naturais Em Unidades De Conservação. Ambiente \& Sociedade - Ano II - No 5, 7992.

BARROS, H. (1975). Os grandes sistemas de organização da economia agrícola. Lisboa: Livraria Sá da Costa Editora.

BARRETO, Patrycia Scavello; MACEDO, Marcelo Álvaro da Silva; ALVES, Francisco José dos Santos. TOMADA DE DECISÃO E TEORIA DOS PROSPECTOS EM AMBIENTE CONTÁBIL: UMA ANÁLISE COM FOCO NO EFEITO FRAMING. Revista de Gestão, Finanças e Contabilidade, ISSN 2238-5320, Salvador, v. 3, n. 2, p. 61-79, maio. 2013.

BRASIL. Constituição Federal de 1988 n. 91, de 05 de out. de 1988. Constituição Federal. Constituição. 91. ed. Brasil, p. 01-34, out. Disponível em: http://www.planalto.gov.br/ccivil_03/constituicao/constituicaocompilado.htm. Acesso em: 07 dez. 2016.

BRASIL. (14 De 09 De 2017). Decreto No 6.040. Fonte: Decreto $N^{\circ} 6.040$, de 7 de fevereiro De 2007. Disponível em: http://www.planalto.gov.br/ccivil_03/_ato20072010/2007/decreto/d6040.htm. Acessado 01 jan. 2016.

CARVALHO JUNIOR, C. V. O.; ROCHA, J. S.; BRUNI, A. L. Efeito Framing em decisões gerenciais e aprendizado formal de controladoria: um estudo experimental. RIC - Revista de Informação Contábil, v. 4, n. 3, p. 35-36, jul-set/2010.

DECRETO No 6.040. (07 de fevereiro de 2007). Decreto $\mathbf{n}^{\mathbf{0} 6040}$. Fonte: DECRETO ${ }^{\circ}$ 6.040, DE 7 DE 7 FEVEREIRO http://www.planalto.gov.br/ccivil_03/_ato20072010/2007/decreto/d6040.htm. Acesso em: 04 mar. 2016. 
FAÇANHA, S. L. O. Contribuições para o Processo Decisório Estratégico de Fazer ou Comprar: Um estudo exploratório no contexto químico brasileiro. 2007. 165 f. Dissertação (Mestrado em Administração) - Faculdade de Economia, Administração e Contabilidade. Universidade de São Paulo, São Paulo, 2007.

FUNDAÇÃO PALMARES. (22 de novembro de 2007). FCP. Fonte: Fundação Palmares: http://geografia.seed.pr.gov.br/modules/noticias/article.php?storyid=47. Acesso em: 01 jam. 2016.

GIUCCI, G. (1992). Viajantes do Maravilhoso: O Novo Mundo. Companhia das Letras.

LEITE, I. B. (2000). Os Quilombos No Brasil: Questões Conceituais E Normativas. Etnográfica, Vol. IV, 333-354.

KAHNEMAN, D.; TVERSKY, A. Prospect Theory: Na Analysis of Decision under Risk. Econometrica, v. 47 (2), p. 263-291, 1979.

KOONTZ, Harold; O`DONNELL, Cyril. Princípios de administração: uma análise das funções administrativas. São Paulo: Pioneira, 1972.

LEITE, I. B. (2000). Os Quilombos No Brasil: Questões Conceituais E Normativas. Etnográfica, Vol. IV, 333-354.

LIMA, Murilo Valverde. Um estudo sobre as finanças comportamentais. RAE - eletrônica, v. 2, n.1, p. 1-19, jan. ljun. $2003 . \quad$ Disponível em: http://www.rae.com.br/eletronica/index.cfm?FuseAction=Artigo\&ID $=1873 \& S e c a 0=2 \% \mathrm{C} 2 \%$

BAPWC\&Volume=2\&numero=1\&Ano=2003. Acesso em: 22 jan. 2018.

LONGARAY, A.A. BEUREN, I, M. Decisões Organizacionais: As Perspectivas Qualitativa, Quantitativa E A Abordagem Multicritérios. Programa de Pós-Graduação em Engenharia de Produção e Sistemas da Universidade Federal de Santa Catarina - Campus Trindade - Florianópolis SC, 1999. Disponível em: http://www.abepro.org.br/biblioteca/ENEGEP2001_TR62_0087. Acesso em: 10 jan. 2017.

LUCENA, W. G. L.; FERNANDES, M. S. A.; SILVA, J. D. G. A Contabilidade Comportamental e os Efeitos Cognitivos no Processo Decisório: Uma Amostra Com Operadores da Contabilidade. Revista Universo Contábil, ISSN 1809-3337, Blumenau, v. 7, n. 3, p. 41-58. Jul/set, 2011.

MACEDO, M. A. S.; FONTES, P. V. S. Analise do comportamento decisório de analistas contábilfinanceiros: um estudo com base na teoria da racionalidade limitada. RCC - Revista Contemporânea de Contabilidade, v. 6, n. 11, p. 159-186, 2009.

MACEDO JR., Jurandir Sell. Teoria dos Prospectos: : Uma Investigação Utilizando Simulação de Investimentos. 2003. 2018 p. Tese (Doutorado em Engenharia de Produção)Programa de Pós Graduação em Engenharia de Produção , Universidade Federal de Santa Catarina - UFSC, Florianópolis, 2003. 1. Disponível em: https://repositorio.ufsc.br/bitstream/handle/123456789/85921/199597.pdf?sequence=1.

Acesso em: 13 set. 2017.

MARTINS, J. D. M.; SANTOS, T. L.; CARVALHO, D. R.; SILVA, J. D. G. O Efeito Framing Na Tomada de Decisão Contábil: Perspectiva dos Profissionais da Contabilidade dos Estados do Rio Grande do Norte e Pará. Contabilidade comportamental: conceitos e aplicações / Coordenador, José Dionísio Gomes da Silva. - Natal, RN: POLYPRINT, 2016. 422 pp.: il

MAYER, V. F.; AVILA, M. G. A influência da estruturação da mensagem em comportamentos relacionados à saúde: um teste experimental. Saúde Soc., São Paulo, v. 2, n. 1, p.1-19, jan-jun/2003.

MINETO, C.A.L. Percepção ao risco e efeito disposição: Uma análise experimental da teoria dos prospectos. 2005. 153 f. (Doutorado) Universidade Federal de Santa Catarina (USFC), Florianópolis, 2005.

Disponível

em: 
https://repositorio.ufsc.br/bitstream/handle/123456789/102956/223460.pdf?sequence=1. Acesso em: 20 de jun. 2017.

PEREIRA, Maria José Lara de Bretas; FONSECA, João Gabriel Marques. Faces da decisão: as mudanças de paradigmas e o poder da decisão. São Paulo: Makron Books, 1997.

PEROVANO, D.G. Manual de metodologia científica para a segurança pública e defesa social. Curitiba: Juruá. 2014.

POMPIAM, M. Behavioral finance and wealth management: how to build optimal portfolios that account for investor biases. John Wiley \& Sons Inc., 2006.

PONTES, L. S., SANTIAGO J. S., SANTOS, J.F.L., \& PESSOA L.G.B. Efeito Framing: Um Estudo acerca da Variação nas Possíveis Decisões de Investimento de Estudantes de uma IES Pública na Paraíba. REUNIR: Revista de Administração, Contabilidade e Sustentabilidade. ISSN: 2237-3667 Vol.4, no 3, pp. 113-129, 2014. Disponível em: http://www.spell.org.br/documentos/ver/38199/efeitoframing--um-estudo-acerca-da-variacao-nas-possiveis-decisoes-de-investimento-de-estudantes-deuma-ies-publica-na-paraiba. Acesso em: 18 fev. 2016.

SANTOS, J. H. F.; BOTELHO, D. Análise comparativa de preços: variáveis influentes na percepção de vantagem de compra. RAM - Revista de Administração da Mackenzie, v. 12, n. 2. São Paulo, mar. /abr. 2011.

SERPA, D. A. F., AVILA M. G. Efeito Framing E Influência Da Experiência Gerencial Em Marketing Em Decisões De Compra: Um Teste Experimental. Revista de Administração, Contabilidade e Sustentabilidade. ISSN: 2237-3667 - Vol.4, $\mathrm{n}^{\circ}$ 3, pp. 113-129, 2014. Disponível em: https://www.researchgate.net/profile/Daniela_Ferreira21/publication/281205429_EFEITO_FRAMIN G_E_INFLUENCIA_DA_EXPERIENCIA_GERENCIAL_EM_MARKETING_EM_DECISOES_DE _COMPRA_UM_TESTE_EXPERIMENTAL/links/55db1f3008ae9d659492a3ca. Acesso em: 04 nov. 2017.

SILVA, G. L., \& SOUZA, R. M. (2009). As Comunidades Tradicionais e as lutas pelos direitos étnicos e coletivos no Sul do Brasil. Revista da Faculdade de Direito da UFG, V.33, N. 2 - ISSN 01017187, 128-142.

SIMON, H. A. Comportamento administrativo: estudo dos processos decisórios nas organizações administrativas. Rio de Janeiro: Aliança para o Progresso, 1965.

STEVENSON, Wiliam J. Teste de significância para proporções: Teste de duas amostras para proporções. In: STEVENSON, William J. Estatística Aplicada à Administração. 01. ed. [S.1.]: HARBRA, 1981. cap. 12, p. 276-303. v. 01. 